\title{
Olax zeylanica: AN ENVIRONMENTALLY SAFE BIO-PESTICIDE FOR THE CONTROL OF THE MAIZE WEEVIL SITOPHILUS ZEAMAIS MOTS. (CURCULIONIDAE)
}

\author{
M.T.H.P. Perera* and M. M. S. C. Karunaratne \\ Department of Zoology, University of Sri Jayewardenepura, Sri Lanka \\ thush.harindra@gmail.com
}

\begin{abstract}
Leaf powders of Ocimum graticimum, Morinda citrifolia, Aegle marmelos, Annona squamosa, Annona reticulata, Olax zeylanica and Ricinus communis were screened for their insecticidal activity under laboratory conditions $\left(30 \pm 1{ }^{\circ} \mathrm{C}\right.$ and $\left.84-86 \% \mathrm{RH}\right)$ against Sitophilus zeamais. The powders at the rate of $15 \mathrm{~g} / 50 \mathrm{~g}$ of maize grains were tested and adult mortality was recorded after 24 hours. O. zeylanica was highly effective against $S$. zeamais eliciting $100 \%$ mortality. Mortality for other six plants was significantly lower ranging from 5.28 to $21.24 \%$. O. zeylanica was tested at five dose rates $(1.0,2.5,5.0,7.5,10.0 \mathrm{~g})$ and mortality of adult weevils was recorded after 6,12 and 24 hours. Mortality of weevils increased with the increase of the dose as well as the exposure time. Also, weevil mortality was 100\% at the dose of $10 \mathrm{~g}$ just after 12 hours. Results of this study indicated that leaf powder of $O$. zeylanica was extremely toxic to $S$. zeamaize weevils. $\mathrm{LD}_{50}$ and $\mathrm{LD}_{99}$ values after 6,12 and 24 hours of exposure were $5.84,2.47,1.84 \mathrm{~g}$ and $38.55,8.33$ and $6.51 \mathrm{~g}$ respectively. The present study revealed that Olax zeylanica has high potential as a bio-pesticide which can compete effectively with hazardous insecticides in managing $S$. zeamais infestations.
\end{abstract}

Keywords: Olax zeylanica, Sitophilus zeamais, Insecticidal activity

\section{INTRODUCTION}

Storage insect pests are a problem throughout the world, especially in the tropics because they reduce the quantity and quality of grain. The control of storage insect pests is largely based on synthetic insecticides and fumigants. Currently, in many countries including Sri Lanka, cereals and pulses stored in warehouses are fumigated using synthetic chemicals such as phosphine. However, these products adversely affect the environment and are hazardous to human health (Lee et al., 2004; Tapondjou et al., 2002). The huge post harvest losses and deterioration of grain quality caused by insect pests is found to be a major obstacle in achieving food security (Rouanet, 1992).

More recently, there has been a growing interest concerning the possible use of plant materials as alternatives to synthetic insecticides. Higher plants are rich source of substances with insecticidal properties (Arnason et al, 1989, Dev and Koul, 1997). Insecticides derived from these plants are desirable because they are convenient to use and environmentally safe. Different plant preparations such as whole plants, powders, solvent extracts, and essential oils are been investigated for their insecticidal activity (Regnault-Roger et al 1993, Rembold 1994, Schmutterrer 1988, Prakash and Rao 1997, Isman 2000, Weaver and Subramanyam 2000). Plant materials with insecticidal properties have been used by farmers for generations throughout the world (Belmain et al., 2001) and traditionally, farmers in Sri Lanka also have used various plant products as protectants against storage pests.

The purpose of the present study was to evaluate the efficacy of some locally available botanical products on the survival of the maize weevil, Sitophilus zeamais. Identification of such botanicals will provide environmentally safe bio-pesticides to control storage pests, thus contributing to increased food security in the country. 


\section{MATERIALS AND METHODS}

\subsection{PLANT MATERIALS}

Fresh leaves of Ocimum graticimum (Gasthala), Morinda citrifolia (Ahu), Aegle marmelos (Beli),Annona reticulata (Weli anoda), Ricinus communis (Thel Endaru), Olax zeylanica (Mella) and Annona squamosa (Seeni anoda) were collected from villages near the University. These were washed and air dried and ground into a fine powder using a domestic electric grinder (Multinational, 2101, India). These powders were kept in air tight jars before using in the experiments.

\subsection{INSECT CULTURES}

Sitophilus zeamais used for bioassays were obtained from laboratory cultures maintained on clean and un-infested maize grains at $30 \pm 1^{\circ} \mathrm{C}$, relative humidity of $85 \pm 1 \%$ and a photoperiod of $12 \mathrm{~h}: 12 \mathrm{~h}$ light: dark regime. One week old adults were used in all the experiments.

\subsection{SCREENING OF PLANT MATERIALS FOR INSECTICIDAL ACTIVITY}

Powdered leaves $(15 \mathrm{~g}$ each) of seven plants were admixed with fifty grams $(50 \mathrm{~g})$ of clean and uninfested maize grains in separate plastic containers $(6.5 \mathrm{~cm}$ diameter $\mathrm{x} 8 \mathrm{~cm}$ height). The powders and grains were then mixed thoroughly with the aid of a glass rod. Batches of thirty, unsexed adult weevils were then introduced into each container. Muslin cloth was used to secure the mouths of the plastic cups to ensure aeration and also to prevent insects escaping from containers. A similar set up with untreated grains served as the control. The number of dead insects in each container was recorded 24 hours after the introduction of insects and percentage adult mortality was calculated separately for each treatment. This experiment was replicated five times.

\subsection{INSECTICIDAL EFFECT OF OLAX ZEYLANICA}

Plastic containers similar to those used in the screening test were used in this bioassay. Powdered plant leaves of Olax zeylanica at the rate of $1.0 \mathrm{~g}, 2.0 \mathrm{~g}, 5.0 \mathrm{~g}, 7.5 \mathrm{~g}$ and $10.0 \mathrm{~g}$ were tested against adult maize weevils. The procedure followed to evaluate the insecticidal effect of Olax zeylanica was similar to the previous screening test. In this bioassay, the number of dead insects in each container was recorded after 6,12 and 24 hours of exposure to treatments and percentage adult weevil mortality was calculated. Five replicates were made for each treatment. Data on percentage weevil mortality were corrected using Abbott's (1925) formula.

\subsection{DATA ANALYSIS}

The percentage mortalities of adults were subjected to one-way analysis of variance (ANOVA). Tukey's multiple comparison test $(\mathrm{p}<0.05)$ was used to determine treatment differences. Data obtained from various concentrations were subjected to probit analysis in order to determine the lethal concentrations that kill 50\% (LC50) and 99\% (LC99) of test insects using Minitab 14.

\section{RESULTS AND DISCUSSION}

Mean percent mortality of the $S$. zeamais after 24 hours exposure to powders of seven plant species at $15 \mathrm{~g}$ concentration is shown in Table1. All the plant powders tested for their insecticidal efficacy were found affecting the mortality among $S$. zeamais. All the plant powders tested for their insecticidal efficacy had some lethal effect on the percentage weevil mortality. Compared with the other six plants, powdered leaves of Olax zeylanica elicited exceptionally high mortality $(100 \%)$ in insects. This was followed by Ocimum graticimum with a $20.00 \%$ mortality and Morinda citrifolia and Aegle marmelos with mortality of $16.00 \%$. An extremely low toxic effect was elicited by Ricinus communis, Annona squamosa and A. reticulata. No weevil mortality was observed with the control. 
It is recorded that leaves of $M$. citrifolia are used by farmers to protect pulses from stored product pests even though the results of the present study indicated very low insecticidal activity in weevils. This may be because that leaves of these two plants act as repellents but not as strong toxicants. These two plants showed very low mortality. Also, it is reported that leaves as well as seeds of $A$. squamosa and $A$.reticulata show strong insecticidal activity against storage insect pests such as Callosobruchus chinensis (Karunaratne and Wanniarachchi 2004, Dharmasena et al. 2001). Furthermore in contrast with the results of the present study, the insecticidal activity of the oil of Aegle marmelos was reportedly effective against storage pests $C$. chinensis, Rhyzopertha dominica and Sitophilus oryzae (Kumar et al. 2008). It is also interesting to note that leaves of $R$. communis are effective as grain protectants against infestations of Tribolium castaneum (Haq and Abbas 2005). Keita et al. (2001) reported that powders made from Ocimum graticimum provided complete protection against Callosobruchus maculatus. It can be suggested that significantly low weevil mortality observed for these plants in the present study may be due to various reasons including insect species and other physiological and environmental factors affecting effectiveness of plants.

Table 1: Mortality of $S$. zeamais with different plant powders 24 hours after treatment

\begin{tabular}{ll}
\hline Plant Species & \% Mortality \pm SD \\
\hline Ocimum graticimum & $21.24 \pm 1.69^{\mathrm{b}}$ \\
Morinda citrifolia & $16.54 \pm 2.40^{\mathrm{b}}$ \\
Aegle marmelos & $15.84 \pm 1.47^{\mathrm{b}}$ \\
Annona squamosa & $6.62 \pm 2.36^{\mathrm{c}}$ \\
Annona reticulata & $5.28 \pm 1.80^{\mathrm{c}}$ \\
Olax zeylanica & $100.00 \pm 0.00^{\mathrm{a}}$ \\
Ricinus communis & $5.94 \pm 1.47^{\mathrm{c}}$ \\
\hline
\end{tabular}

Means followed by similar letters are not significantly different from each other ( $p>0.05$ Tukey's test); Mean values for five replicates ( Mean \pm SD ).

Figure 1 demonstrates the effect of various doses of $O$ zeylanica plant powder on the mortality of the adults of $S$. zeamais. All the concentrations tested for their insecticidal efficacy were directly proportional to the amount of powder used for treatment of grains and period of exposure. Mortality of the weevils increased significantly $(p<0.05)$ with the increase of powder concentration ranging from $3 \%$ to $76 \%$ within 6 hours after treatment. After 24 hours of application, all tested concentrations except the lowest two $(1.0$ and $2.5 \mathrm{~g})$, killed almost all the insects. At $1.0 \mathrm{~g}$ concentration, significantly very low mortality was obtained within 6,12 and $24 \mathrm{~h}$ post-treatment. It is also of interest to note that $100 \%$ mortality occurred just after 12 hours of post-treatment when weevils were treated with $10 \mathrm{~g}$ of leaf powder. Furthermore, even with $2.5 \mathrm{~g}$ of leaf powder, more than $50 \%$ mortality was recorded after 12 hours.

Leaves of $O$. zeylanica may have been very potent because of the strong revolting odour they produce when ground to a powder. The ability of this plant material to affect the mortality within a few hours after treatment can be attributed to the fumigant effect of the plant powder on the weevils. According to Adedire and Ajayi (1996), this may have exerted a toxic effect by disrupting the respiratory activity of the weevils, resulting in asphyxiation followed by death. On the other hand, adult mortality might also be attributed to the contact toxicity or to the abrasive effect of the 
powder on the pest cuticle (Mathur et al. 1985), which might also interfere with the respiratory mechanism of the insect (Van Schoonhoven 1978; Agarwal et al. 1988, Kim et al. 2003).

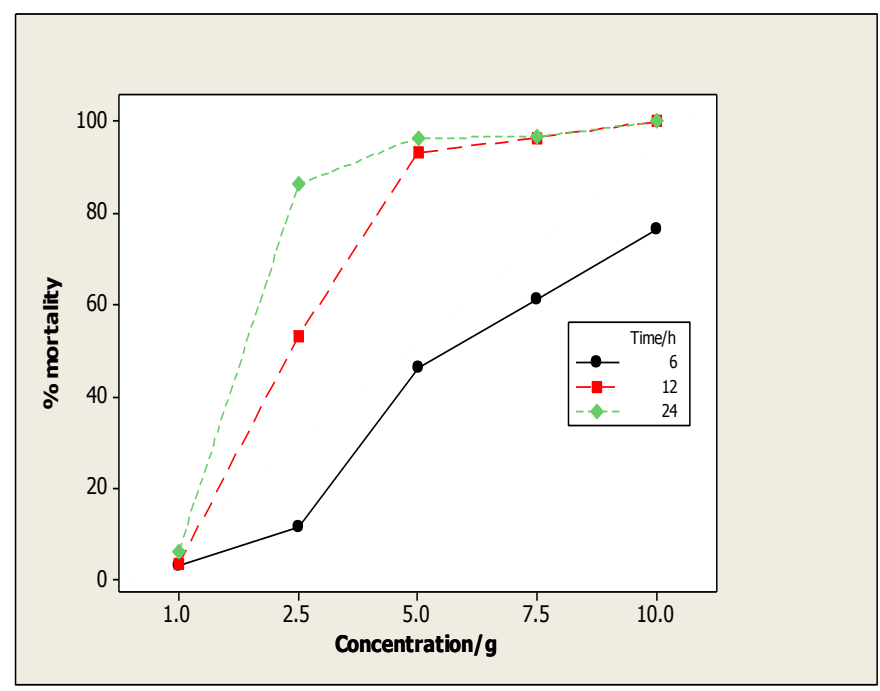

Figure 1: Insecticidal effect of Olax zeylanica leaf powder on adult S. zeamais at different concentrations and time periods

When probit regression lines of the five concentrations at three different time periods were analyzed, they showed a linear relationship between mortality percentage and powder concentration at 12 and 24 hours after treatment (Figures $2 \mathrm{a}$ and b). Estimates of $\mathrm{LD}_{50}$, $\mathrm{LD}_{99}$ values and their standard errors and 95\% Fiducial Confidence Limits for 6, 12 and 24 hours posttreatment are presented in Table 2. Values for $\mathrm{LD}_{50}$ were $5.84 \mathrm{~g}$ (5.26-6.52) and 2.47g (2.24-2.71) at 6 and 12 hours after treatment respectively. On the other hand, values for $\mathrm{LD}_{99}$ were $38.55 \mathrm{~g}$ (28.29-59.53) and 8.33g (7.11-10.21) at the same time periods. However, $\mathrm{LD}_{50}$ and $\mathrm{LD}_{99}$ values after 24 hours of exposure were 1.84 and $6.51 \mathrm{~g}$ respectively. These results demonstrate that powdered leaves of $O$. zeylanica were effective against the adult weevils at all time periods. It was quite striking to note that with the increase of exposure time, the $\mathrm{LD}_{50}$ and $\mathrm{LD}_{99}$ values decreased showing the lowest values at 24 hours of exposure. This means if the exposure time for the weevils is long then the dosage required to kill $50 \%$ or $99 \%$ of test insects would be very much less.

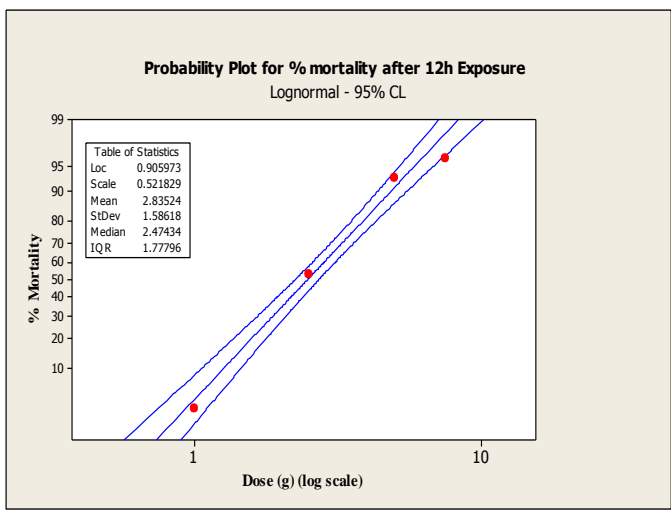

(a)

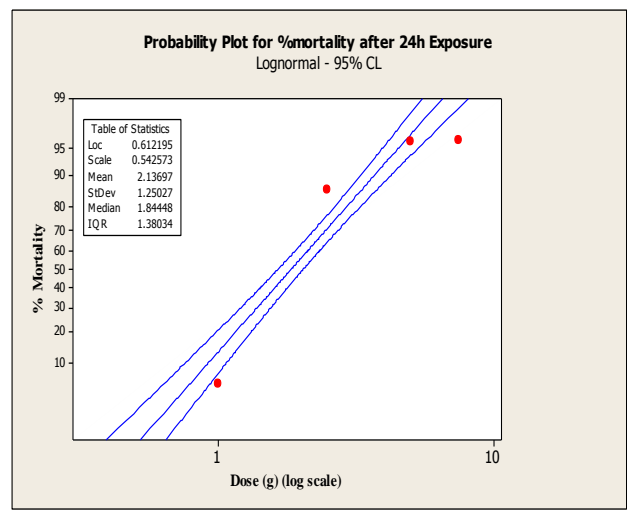

(b)

Figure 2: Log dosage-probit mortality lines $\left(\mathrm{LD}_{50}\right.$ and $\left.\mathrm{LD}_{99}\right)$ for leaf powder of Olax zeylanica against adult Sitophilus zeamais after a) 12 hours and b) 24 hours of exposure 
Table 2: Probit analysis for insecticidal effect of Olax zeylanica leaf powder on Sitophilus zeamais after 6, 12 and 24 hours of exposure

\begin{tabular}{|c|c|c|c|c|c|}
\hline Time & $\begin{array}{l}\text { No. of insects } \\
\text { used }\end{array}$ & $\begin{array}{l}* \mathrm{LD}_{50} \\
\text { (95\% Fiducial } \\
\text { Confidence Limits) }\end{array}$ & $\mathrm{SE}( \pm)$ & $\begin{array}{l}* * \mathrm{LD}_{99} \\
\text { (95\% Fiducial } \\
\text { Confidence Limits) }\end{array}$ & $\mathrm{SE}( \pm)$ \\
\hline 6 HAT & 150 & $\begin{array}{l}5.84 \\
(5.26-6.52)\end{array}$ & 0.31 & $\begin{array}{l}38.55 \\
(28.29-59.53)\end{array}$ & 7.10 \\
\hline $12 \mathrm{HAT}$ & 150 & $\begin{array}{l}2.47 \\
(2.24-2.71)\end{array}$ & 0.11 & $\begin{array}{l}8.33 \\
(7.11-10.21)\end{array}$ & 0.75 \\
\hline 24 HAT & 150 & $\begin{array}{l}1.84 \\
(1.65-2.03)\end{array}$ & 0.09 & $\begin{array}{l}6.51 \\
(5.50-8.11)\end{array}$ & 0.63 \\
\hline
\end{tabular}

HAT - Hours after Treatment

95\% lower and upper fiducial limits are shown in parenthesis

$* \mathrm{LD}_{50}$ - Lethal dosage that kills $50 \%$ of the population

** $\mathrm{LD}_{99}$ - Lethal dosage that kills $99 \%$ of the population

World-wide research on the toxicity of different plant derivates including powders of plant leaves show that many of these are toxic to stored product insects (Weaver et al. 1994, Talukder and Howse, 1995, Xie et al. 1995, Tripathi et al. 2000, Park et al. 2003, Boeke et al. 2004, Talukder et al. 2004, Islam and Talukder 2005).

Despite the fact that leaves of Olax zeylanica had been used by farmers in Sri Lanka since olden times to protect stored grain from insect pests, no scientific research has ever been carried out until now on the toxic effects of this plant. O. zeylanica being a medicinal plant and is consumed by people in Sri Lanka would be rather a great advantage, as chemical compounds identified and isolated from this plant would be environmentally sound having no harmful effects on non target organisms.

Based upon the present study, it could therefore, be stated that leaf powder of O. zeylanica possesses insecticidal activity worth exploiting for the management of stored commodities from insect pests including maize weevil infestations. Moreover, these findings suggest that this powder can directly serve as a highly potent and eco-friendly natural bio-pesticide or possibly as a guide for the synthesis of novel insecticides. 


\section{REFERENCES}

Abbott, W. S. 1925. A Method of Computing the effectiveness of an Insecticide. Journal of Economic Entomology 18: $265-267$

Adedire, C. O. and Ajayi, T. S. 1996. Assessment of the insecticidal properties of some plant extract as grain protectant against maize weevil Sitophilus zeamais (Motchulsk). Nig. J. Entomol. 13: 93 - 101.

Agarwal, A., Lal, S. and Gupta, K. C. 1988. Natural products as protectants of pulse betles. Bull. Grain Tech. 26:154-164.

Arnason, J.T., Philogene, B. J. R., Morand, P. 1989. Insecticides of plants origin. American Chemical Society Symposium Series Vol. 387. Washington.

Belmain, S.R. and Stevenson, P. C. 2001. Ethnobotanicals in Ghana: reviving and modernising age-old farmer practice. Pesticide Outlook 12, 233-238.

Boeke, S. J., Baumgart,I. R., Loon, J. J. A. V., Huis, A. V., Dicke, M. and Kossou, D. K. 2004. Toxicity and repellence of African plants traditionally used for the protection of stored cowpea against Callosobruchus maculatus. J. Stored Prod Res. 40(4):423-438.

Dev, S. and Koul, O. 1997. Insecticides of natural origin Hardwood Academic Publishers Amsterdam pp.365.

Dharmasena, C. M. D., Blaney, W.M. and Simmonds, M. S. J. 2001. Effect of storage on the efficacy of powdered leaves of Annona squamosa for the control of Callosobruchus maculatus on cowpeas (Vigna unguiculata). Phytoparasitica 29: 191-196.

Haq, T. Usmani, N. F. and Abbas, T. 2005. Screening of plant leaves as grain protectants against Tribolium castaneum during storage. Pak. J. Bot., 37(1): 149-153

Islam, M. S. and Talukder, F. A. 2005. Toxic and residual effects of Azadirachta indica, Tagetes erecta and Cynodon dactylon extracts against Tribolium castaneum. J. Plant Diseases Protect. 112(6):594-601. Isman M. B. 2000. Plant essential oils for pest diseases management. Crop Prot. 19: 603-608

Karunaratne, M.M.S.C. and Wanniarachchi, W.S. 2004. Comparative effects of neem and certain species of Annona on the cowpea beetle, callosobruchus chinensis. Sri Lanka association for the Advancement of Science, Proceedings of the $60^{\text {th }}$ Annual Session. Part 1- Abstract, 173

Keita, S. M., Vincent, C., Schmit, J. P., Arnason, J. T. and Belanger, A. 2001. Effect of essential oil of Ocimum basilicum L. and $O$. gratissimum L. applied as fumigant and powder to control Callosobruchus maculatus (Fab.) (Coleoptera: Bruchidae). J. Stored Prod. Res. 37, 339-349.

Kim, S. I., Roh, J.Y., Kim, D.H., Lee, H.S. and Ahn, Y.J. 2003. Insecticidal activities of aromatic plant extracts and essential oils against Sitophilus oryzae and Callosobruchus chinensis. J. Stored Prod. Res. 39: 293-303.

Kumar, R., Kumar, A., Prasa1, C. S., Dubey, N. K. and Samant, R. 2008. Insecticidal Activity Aegle marmelos (L.) Correa Essential Oil Against Four Stored Grain Insect Pests. Internet Journal of Food Safety, Vol.10, 2008, p.39-49.

Lee, B.H., Annis, P. C., Tumaalii, F. and Choi, W.S. 2004. Fumigant toxicity of essential oils from the Myrtaceae family and 1,8-cineole against 3 major stored grain insects. Journal of Stored Products Research 40, 553-564.

Mathur, Y. K., Shankar, K, and Ram, S. 1985. Evaluation of some grain protectants against Callosobruchus chinensis (L.) on black gram. Bull. Grain Tech. 23: 253-259.

Park, C., Kim, S. I. and Y .J. Ahn, Y. J. 2003. Insecticidal activity of asarones identified in Acorus gramineus rhizome against three coleopteran stored-product insects. J. Stored. Prod Res. 39 (3):333-342.

Proceedings of the $15^{\text {th }}$ International Forestry and Environment Symposium, 26-27 November 2010.

Published by Department of Forestry and Environmental Science, University of Sri Jayewardenepura, Sri Lanka. 
Prakash, A. and Rao, J., 1997. Botanical Pesticides in Agriculture. CRC Press Inc., Baton Rouge, Florida.

Regnault-Roger, C., Hamraoui, A., Holeman, M., Theron, E. and Pinel, R. 1993. Insecticidal effect of essential oils from Mediterranean plants upon A. obtectus Say (Coleoptera, Bruchidae), a pest of kidney bean (Phaseolus vulgaris L.). J Chem Ecol 19(6): 1231-1242.

Rouanet, G. 1992. Maize. The Tropical Agriculturist, CTA, Macmillan, London 102pp.

Schmutterer, H. 1988. Potential of azadirachtin-containing pesticides for integrated pest control in developing and industrialized countries. Journal of Insect Physiology 34:713-719.

Talukder, F. A. and Howse, P. E. 1995. Evaluation of Aphanamixis polystachya as repellents, antifeedants, toxicants and protectants in storage against Tribolium castaneum (Herbst). J. Stored Prod. Res. 31:55- 61.

Talukder, F. A., Islam, M. S., Hossain, M .S., Rahman, M. A and Alam, M. N. 2004. Toxicity Effects of botanicals and synthetic insecticides on Tribolium castaneum (Herbst) and Rhyzopertha dominica (F.). Bangladesh J. Environ. Sci. 10(2):365-371.

Tapondjou, L. A., Adler, C. Bouda,H. and Fontem, D. A. 2002. Efficacy of powder and essential oil from Chenopodium ambrosioides leaves as post-harvest grain protectants against six-stored product beetles. $J$. stored Prod. Res. 38:395-402.

Tripathi A. K., Prajapati, V., Aggarwal, K. K., Khanuja, S. P. S. and Kumar, S. 2000. Repellency and toxicity of oil from Artemisia annua to certain stored product beetles. J. Econ. Entomol., 93: 43-47.

Van Schoonhoven, A. (1978). Use of vegetable oils to protect stored beans bruchid attack. Journal of Economic Entomology 71, 254-256.

Weaver D.K., Dunkel, F. V., Potter, R. C. and Ntezurubanza, L. 1994. Contact and Contact and fumigant efficacy of powdered and intact Ocimum canum Sims (Lamiales: Lamiaceae) against Zabrotes subfasciatus (Boheman) adults (Coleoptera:Bruchidae). Journal of Stored Products Research, 30: 243-252.

Weaver, D. and Subramanyam, B. H. 2000. Botanicals. In: Subramanyam, Bh, Hagstrum, D. (Eds.), Alternatives to Pesticides in Stored-Product IPM. Dordrecht, Kluwer Academics Publishers, pp. 303-320.

Xie, Y. S., Fields, P. G., Isman, M. B., Chen, W. K. and Zhang, X. 1995. Insecticidal activity of Melia toosendon extracts and Toosendanin against three stored-product insects. J. stored prod. Res. Vol.31, No. 3 , pp259-265. 